\title{
Conserved B-cell epitope identification of envelope glycoprotein (GP120) HIV-1 to develop multi-strain vaccine candidate through bioinformatics approach
}

\section{Viol Dhea Kharisma $\oplus^{1}$, Arif Nur Muhammad Ansori $\oplus^{2}$, Gabrielle Ann Villar Posa $\oplus^{3}$, Wahyu Choirur Rizky ${ }^{4}$, Sofy Permana ${ }^{1}$, Arli Aditya Parikesit ${ }^{5^{*}}$}

1 Department of Biology, Faculty of Mathematics and Natural Sciences, Universitas Brawijaya, Malang, Indonesia

2 Doctoral Program in Veterinary Science, Faculty of Veterinary Medicine, Universitas Airlangga, Surabaya, Indonesia

3 School of Environmental Science and Management, University of the Philippines Los Baños, Los Baños, Philippines

4 College of Medicine, Sulaiman Al Rajhi University, Al Bukayriyah, Al-Qassim, Saudi Arabia

b Department of Bioinformatics, School of Life Sciences, Indonesia International Institute for Life Sciences, Jakarta, Indonesia

Abstract: HIV-1 gp120 can be recognized by the immune system because it is located outside the virion. The conserved region is identified in gp120, and it is recognized by an immune cell which then initiates specific immune responses, viral mutation escape, and increase vaccine protection coverage, a benefit derived from the conserved region-based vaccine design. However, previous researchers have little knowledge on this conserved region as a target for vaccine design. This paper explains how the conserved region of gp120 HIV-1 is a major target for vaccine design through a bioinformatics approach. The conserved region from gp120 was explored as a vaccine design target with a bioinformatics tool that consists of B-cell epitope mapping, vaccine properties, molecular docking, and dynamic simulation. The peptide vaccine candidate of B5 with the gp120 HIV-1 conserved region was found to provoke B-cell activation through a direct pathway, produce specific antibody, and increase protection from multi-strain viral infection.

Keywords: AIDS; Bioinformatics; Conserved Region; HIV; Vaccine Design

\section{INTRODUCTION}

Acquired immune deficiency syndrome (AIDS) has been identified from US patients since 1981. AIDS is caused by infection with the human immunodeficiency virus type 1 (HIV-1) which is a retrovirus. AIDS is an opportunistic conditionwherein the immune system fails to respond to pathogens such as bacteria, fungi, protozoa, and other viruses. ${ }^{1}$ Viral attachment of HIV-1 is regulated by structural and non-structural proteins. A structural protein is located in the envelope and consists of gp120 and gp41. gp120 is formed through protein cleavage with furin and protease in the endoplasm reticulum.?

HIV-1 infectivity is higher than HIV-2 due to differences in mutation rates. ${ }^{3}$ Epidemic cases of HIV-1 are more common because mutations have produced various strains. HIV-2 has less virulent strains and is endemic in West Africa. ${ }^{4}$ The current HIV-1 strains consist of A, B, C, D, E, F, G, H, \& J from Asia, Africa, 
Australia, Europe, and America. $\frac{5}{}$ The gp120 protein from these various strains was the main target of the vaccine design in this study.

Currently, vaccine candidates entering the clinical trial stage consisting of HTVN702, CR106152, CR108068, and HTVN106 do not use conserved regions as vaccine design targets. Previous studies have shown the discovery of conserved regions in gp120. These regions play an important role in the formation of the gp120-host receptor complex, produce specific immune responses, and increase vaccine protection coverage. $\underline{6}$ However, previous researchers know little about this conserved region HIV-1 as a target for vaccine design, leading to less protection from viral mutation.

Based on this, the HIV-1 vaccine with conserved regions in gp120 must be developed through a bioinformatics approach to predict the molecular mechanism of peptides vaccine candidates and provoke an immune response. The vaccine design method used in bioinformatics consists of prediction of B-cell epitopes on HIV-1 gp120, antigenicity, similarity, molecular docking, and dynamic simulation..$^{-}$This study used a conserved region of gp120 from various HIV-1 strains as a vaccine design target through the bioinformatics approach. The peptides of the vaccine candidate are expected to initiate B-cell activation, production of specific antibodies, and increased protection coverage. This study aims to determine the potential for conserved regions in gp120 HIV-1 as a candidate for multi-strain vaccines through a bioinformatics approach.

\section{MATERIAL AND METHOD}

\section{a. Conserved Identification of gp120 HIV-1}

NCBI database (www.ncbi.nlm.nih.gov) was used to collect HIV-1 envelope gp120 protein sequences with the keyword "HIV-1 envelope glycoprotein". Then, a screening sample was carried out to identify the full record sequence. Information such as country of origin, strain, and length (mer) was obtained. ${ }^{8,9}$ MEGA $X$ for 64 -bit Windows software was used to identify the conserved region position on gp120 HIV-1 through sequence alignment. Construction of the 3D gp120 HIV-1 template structure was done through SWISS-MODEL (https://swissmodel.expasy.org/) with the homology modelling, then model validation and structure quality determine were carried out on the Ramachandran..$^{10,11}$

\section{b. B-cell Immune Epitope Prediction}

Prediction of B-cell epitopes in the gp120 HIV-1 region was performed using BepiPred 1.0 and Emini Surface Accessibility through the IEDB server ( $h$ ttp://tools.iedb.org/bcell/). Both methods were used to identify probabilities as $B$-cell epitopes in the antigen region with positive predictions. These predictions were based on values above the threshold, calculation of the probability scale, and Hidden Markov Model for probability prediction of the epitope-based on the amino acid query sequence. $\frac{12}{}$

\section{c. Properties Analysis \& Peptide Modeling}

The peptide sequences obtained from B-cell epitopes on HIV-1 gp120 were then analyzed for their antigenicity, similarity, toxicity, and physiochemical. VaxiJen v2.0 (http://www.ddg-pharmfac.net/ vaxijen/VaxiJen/VaxiJen.html) was used for antigenic peptides prediction. ${ }^{12}$ The antigenic peptide was identified with $<70 \%$ similarity through BLASTp (https://blast.ncbi.nlm.nih.gov/ Blast.cgi?PAGE=Proteins)..$\underline{13}$ An antigenic peptide with a low similarity score identified the level of toxicity in ToxinPred (http://crdd.osdd.net/raghava/toxinpred) (Gupta et al. 2013). A 3D structure construction of the candidate peptide was carried out on the PEP-FOLD 3.5 server (https://mobyle.rpbs.univ-paris-diderot.fr/cgi-bin/portal.py\#forms). 


\section{d. Molecular Docking and Dynamic}

Molecular docking with Cluspro 2.0 server was performed on the peptide binding simulation of $\mathrm{B}$-cell receptor (BCR) to determine binding energy in peptide-BCR molecule complex form. This method was done by superimposing the atoms to the lowest energy to determine possible binding positions. ${ }^{14,15}$ A 3D structure visualization was displayed through PyMol software with molecular selection. ${ }^{16}$ The result of docking simulation was used to analyze the chemical bond interaction and position on the peptide-BCR complex through Discovery Studio 2017. 17 Molecular dynamic simulations were carried out through CABSflex 2.0 server (http://biocomp.chem.uw.edu.pl/CABSflex2/index) to determine stable RMSF of vaccine candidate peptides in hotspot interaction with BCR activity. $\frac{18}{}$

\section{RESULTS AND DISCUSSION}

This study used $80 \mathrm{HIV}-1$ envelope isolates from the continents of Asia, Europe, Australia, America, and Africa with types of strains A, B, C, D, E, F, G, H, $\& \mathrm{~J}$ that were obtained from NCBI. The results of the alignment analysis proved that 50 isolates were showing the conserved region identified on the inner, outer, and bridging sheet of gp120 HIV-1. The inner, bridging sheet and outer regions of gp120 HIV-1 through in vitro studies can be used as vaccine design targets as they have a role in the viral fusion initiation process, interacting directly with CD4+ receptors and CCR5 co-receptors during viral attachment mechanisms, and generating responses such as neutralization of antibodies. ${ }^{19}$ The conserved region is a DNA or protein sequence that is retained during each virus generation and may serve as a vaccine design target. $\underline{20}$ The results of this study showing a conserved region in the HIV-1 gp120 structure can act as a vaccine design target and initiate the production of antibodies to bind the specific region recognized by immune cells.

Activation of B-cell through the direct pathway plays a role in initiating the production of $\operatorname{lgM}$ isotype antibodies which play a role in the neutralization, opsonization, and efficiency of phagocytosis against viruses. ${ }^{21}$ The gp120 HIV-1 can be recognized as epitopes by B-cell. Eight peptides were obtained through BepiPred and Emini Surface Accessibility parameters. This prediction generates threshold values of 0,35 and 1,00 (Figure 1). Sequences on gp120 HIV-1 with values above the threshold included positive predictions, B-cell epitopes that were identified in this study were two peptides from the outer area, five inner peptides, and one bridging sheet peptide (Table 1). Regions from the gp120 HIV1 consist of outer, inner, and bridging sheets that could be recognized by B-cell and initiate activation through the direct pathway.
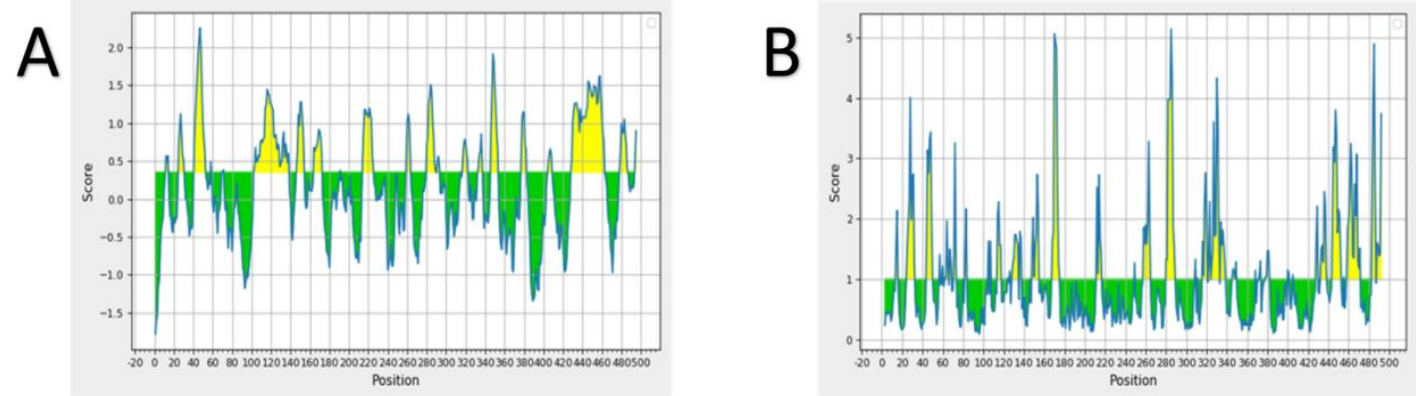

Figure 1. B-cell epitope mapping of gp120 HIV-1, positive predictions are shown in yellow areas while green is negative. Prediction graphs (A) BepiPred \& (B) Emini Surfaces Accessibility. 
Table 1. B-cell epitope prediction of gp120 HIV-1

\begin{tabular}{|c|c|c|c|c|c|}
\hline Position & $\begin{array}{l}\text { Prediction } \\
\text { Methods }\end{array}$ & $\begin{array}{l}\text { Peptide } \\
\text { Length } \\
\text { (mer) }\end{array}$ & $\begin{array}{l}\text { Peptide } \\
\text { Number }\end{array}$ & Epitope & $\begin{array}{l}\text { Locati } \\
\text { on }\end{array}$ \\
\hline $41-52$ & BepiPred & 12 & B1 & $\begin{array}{l}\text { CVPTDPNPHEEF } \\
\text { NVNDTNVNCTTNSTTN }\end{array}$ & Inner \\
\hline $103-138$ & BepiPred & 36 & B2 & $\begin{array}{l}\text { GNCTTKGNISEWERVE } \\
\text { QGDL }\end{array}$ & Inner \\
\hline $214-225$ & $\begin{array}{l}\text { BepiPred } \\
\text { BepiPred, }\end{array}$ & 12 & B3 & KKFSGTGPCKNV & Inner \\
\hline $280-289$ & $\begin{array}{l}\text { Emini Surface } \\
\text { Accessibillity }\end{array}$ & 10 & B4 & TRPNNNTRKS & Outer \\
\hline $428-462$ & BepiPred & 35 & B5 & $\begin{array}{l}\text { DGGNRINSTDNSTIGYS } \\
\text { NDNNTETFRPGGGNMK } \\
\text { DN }\end{array}$ & $\begin{array}{c}\text { Outer, } \\
\text { Inner, } \\
\text { Bridgin } \\
g \\
\text { Sheet }\end{array}$ \\
\hline 458- 471 & $\begin{array}{l}\text { Emini Surface } \\
\text { Accessibillity }\end{array}$ & 14 & B6 & NMKDNWRSELYKYK & Inner \\
\hline
\end{tabular}

Peptide vaccine candidates derived from B-cell epitopes of gp120 are identified using vaccine properties prediction which consists of antigenicity, similarity, and toxicity. Antigenic peptides must have an antigenicity threshold value of $\geq 0.4 . \stackrel{22}{ }$ Furthermore, the similarity value must be $>70 \%$ so that it can initiate the antibodies escaping from an autoimmune response, and the toxicity level is below the threshold of $0,1 . \underline{8,23}$ The result of antigenicity and similarity prediction shows that the three peptides from the B-cell epitope consists of B2, B3 \& B4. The antigen had values above the threshold of $\geq 0.4$ and had a low $<70 \%$ which is similar to the sequences from cell receptors surface from a human. The results of toxicity analysis showed that peptides B2, B3, \& B4 were non-toxic because their values were lower than the 0.1 thresholds (Table 2). The presence of conserved residues on the peptides from B-cell epitope can trigger specific immune cell responses because they are antigenic, have low similarity, not toxic, and escape autoimmune reactions. The antibodies can bind to the conserved region of gp120 HIV-1. Peptide B5 was identified as having a conserved region consisting of 'DRGG' residue numbers $1,26,29, \& 30$ at the inner and outer locations of gp120 HIV-1.

Table 2. Vaccine properties of B-cell epitope

\begin{tabular}{|c|c|c|c|c|}
\hline \multirow{2}{*}{$\begin{array}{l}\text { Peptide } \\
\text { Number }\end{array}$} & \multirow{2}{*}{ Peptide } & \multicolumn{3}{|c|}{ Vaccine Properties } \\
\hline & & Antigenicity & Similarity & Toxicity \\
\hline B1 & CVPTDPNPHEEF & $\begin{array}{l}\text { Non-Antigen } \\
(0,37)\end{array}$ & - & - \\
\hline B2 & $\begin{array}{l}\text { NVNDTNVNCTTNSTTNGNC } \\
\text { TTKGNISEWERVEQGDL }\end{array}$ & $\begin{array}{l}\text { Antigen } \\
(0,88)\end{array}$ & $\begin{array}{l}\text { Non-Similar } \\
(<70 \%)\end{array}$ & $\begin{array}{l}\text { Non-Toxin } \\
(-0,83)\end{array}$ \\
\hline B3 & KKFSGTGPCKNV & $\begin{array}{l}\text { Non-Antigen } \\
(0,20)\end{array}$ & - & - \\
\hline B4 & TRPNNNTRKS & $\begin{array}{l}\text { Antigen } \\
(0,56)\end{array}$ & $\begin{array}{l}\text { Non-Similar } \\
(<70 \%)\end{array}$ & $\begin{array}{c}\text { Non-Toxin } \\
(-0,50)\end{array}$ \\
\hline B5 & $\begin{array}{l}\text { DGGNRINSTDNSTIGYSND } \\
\text { NNTETFRPGGGNMKDN }\end{array}$ & $\begin{array}{l}\text { Antigen } \\
(0,41)\end{array}$ & $\begin{array}{l}\text { Non-Similar } \\
(<70 \%)\end{array}$ & $\begin{array}{l}\text { Non-Toxin } \\
(-1,03)\end{array}$ \\
\hline B6 & NMKDNWRSELYKYK & $\begin{array}{l}\text { Non-Antigen } \\
\quad(0,14)\end{array}$ & - & - \\
\hline
\end{tabular}


This study used a 3D structure of BCR (ID: 5IFH) which was obtained from the RCSB PDB database (https://www.rcsb.org). Docking simulation of B5 and BCR was performed with fast rigid-body method on Cluspro 2.0 to determine the lowest energy value which is from the molecular complex after superimposing action. ${ }^{14}$ Then, the docking results of peptide-protein interactions were identified through Discovery Studio to determine the position, distance, and types of chemical bond interactions in molecular complexes. ${ }^{24}$ Weak bond interactions from molecular docking are non-covalent types consisting of electrostatic, Van der Waals, hydrophobic, pi, and hydrogen interactions. $\frac{25}{}$ This type of bonding interaction plays a role in protein response activity when there is a ligand interaction in the specific binding region. Types of bonds and specific amino acid residues can initiate various responses in proteins such as activation, inhibition, stability, etc. $\frac{26}{}$

B10 peptide binds to the BCR region initiating electrostatic, hydrogen, and hydrophobic interactions. About four amino acid residues make up the B5 peptide resulting in twelve interactions in the L chain regions: Glu163, Thr164, \& Thr166) and H: Lys43, Asp117, Thr113, Val114, Ser115, Glyc42, \& Pro41) on BCR. The lowest energy value was $-510.1 \mathrm{kcal} / \mathrm{mol}$. Visualization of the docking results was carried out on PyMol software in transparent surfaces and cartoon's structure. The result of molecular dynamic analysis showed that B5 peptide has residual fluctuations when interacting with regions $L$ and $H$ chain on BCR. RMSF values consisted of 1.0-1.5 $\AA$ in peptides and 2.0-3.0 $\AA$ in forming stable molecular complexes (Figure 2).

Binding between antigens and Lys \& Val residues in the H-chain BCR can initiate $B$ lymphocyte activation, proliferation, and maturation into plasma cells. ${ }^{27}$ With the RMSF value being $\leq 4.0 \AA$, a stable molecular complex can trigger fluctuating residues that contribute to receptor response activity. $\frac{28}{.}$ The results showed that the conserved region consists of Asp30 \& Arg26 from peptide B5 that binds to $\mathrm{H}$ chain $\mathrm{BCR}$ with hydrogen bonds. It initiates biological responses activation with residues stable binding of Lys 43 and Val114 through hydrogen bonds interaction. Peptide B5 is predicted to be an effective vaccine candidate because it can be recognized by $B$ cells as an epitope, is antigenic, has low similarity, is not toxic, and forms a stable molecular complex with BCR. Peptide B5 allows being constructed in further tests in a wet lab. However, the immune response triggered by $B$ cell epitope recognition in this study has not yet produced memory because there is no mechanism for $B$ cell activation through helper T cells.
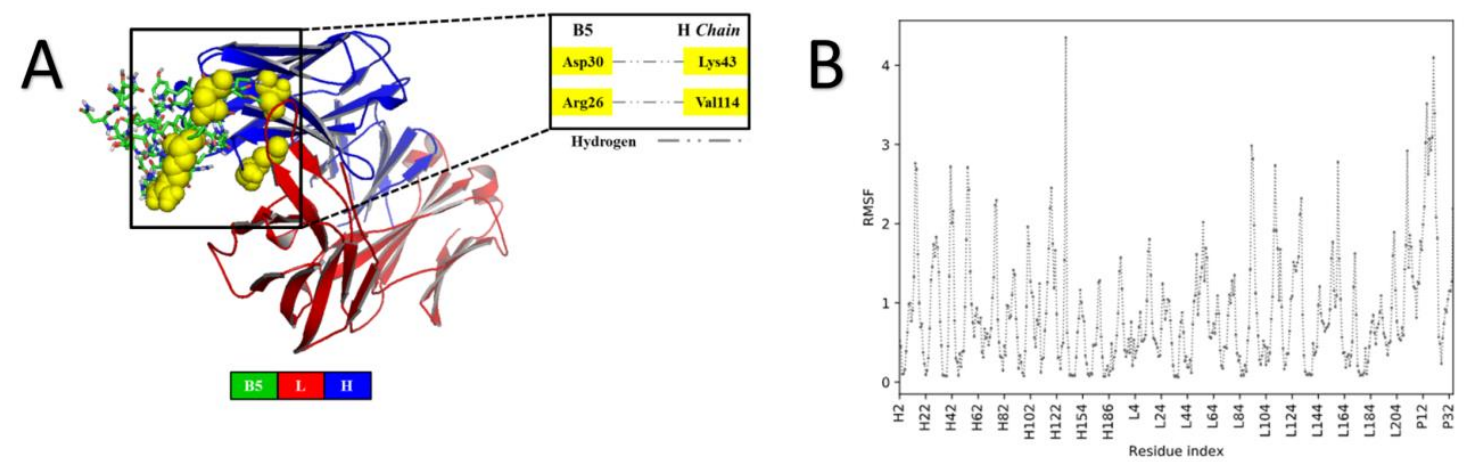

Figure 2. Molecular docking and dynamic simulations representation. (A) 3D structure visualization and interaction hotspots (B) RMSF graph of fluctuative peptide $B 5$ and $B C R$ residues. 


\section{CONCLUSION}

Peptide B5 can be used as a good candidate for the HIV-1 vaccine because it has a conserved region to initiate B-cell activation through the BCR functional region, production of specific antibodies, and increased protection against multi-strain viral infections. It is further recommended that the results of this research be further tested through in vitro and in vivo approach.

\section{AUTHORS' CONTRIBUTIONS}

Viol Dhea Kharisma and Arif Nur Muhammad Ansori prepared the samples, designed the protocols, executed the protocols, and wrote the manuscript. Arif Nur Muhammad Ansori, Gabrielle Ann Villar Posa, and Wahyu Choirur Rizky reviewed the manuscript. Sofy Permana and Arli Aditya Parikesit reviewed and supervised the manuscript. All authors have read and approved the final manuscript.

\section{FUNDING INFORMATION}

This research received no specific grant from any funding agency in the public, commercial or not-for-profit sectors.

\section{DATA AVAILABILITY STATEMENT}

The utilized data to contribute in this investigation are available from the corresponding author on reasonable request.

\section{DISCLOSURE STATEMENT}

The views and opinions expressed in this article are those of the authors and do not necessarily reflect the official policy or position of any affiliated agency of the authors.

\section{REFERENCES}

1. Douek DC, Roederer M, Koup RA. Emerging concepts in the immunopathogenesis of AIDS. Annu Rev Med. 2009;60:471-484. doi:10.1146/annurev.med.60.041807.123549.

2. Acharya P, Lusvarghi S, Bewley CA, Kwong PD. HIV-1 gp120 as a therapeutic target: Navigating a moving labyrinth. Expert Opin Ther Targets. 2016;19(6):765-783. doi:10.1517/14728222.2015.1010513.

3. Cuevas JM, Geller R, Garijo R, López-Aldeguer J, Sanjuán R. Extremely high mutation rate of HIV-1 in vivo. PLOS Biol. 2015;13(9):1-19. doi:10.1371/journal.pbio.1002251.

4. Campbell-Yesufu OT, Gandhi RT. Update on human immunodeficiency virus (HIV)-2 infection. Clin Infect Dis. 2011;52(6):780-787. doi:10.1093/cid/ciq248.

5. Castley A, Sawleshwarkar S, Varma R, et al. A national study of the molecular epidemiology of HIV-1 in. PLoS One. 2017;12(5):1-17. doi:10.1371/journal.pone.0170601.

6. Gao Y, McKay PF, Mann JFS. Advances in HIV-1 vaccine development. Viruses. 2018;10(4):1-26. doi:10.3390/v10040167.

7. Zahroh $\mathrm{H}$, Ma'rup A, Tambunan USF, Parikesit AA. Immunoinformatics approach in designing epitopebased vaccine against meningitis-inducing bacteria (Streptococcus pneumoniae,Neisseria meningitidis, and Haemophilus influenzae type b). Drug Target Insights. 2016;10:19-29. doi:10.4137/DTI.S38458. 
8. Adianingsih OR, Kharisma VD. Study of B cell epitope conserved region of the Zika virus envelope glycoprotein to develop multi-strain vaccine. J Appl Pharm Sci. 2019;9(1):98-103. doi:10.7324/JAPS.2019.90114.

9. Ansori ANM, Kharisma VD, Nugraha AP. Phylogenetic and pathotypic characterization of avian paramyxovirus serotype 1 (APMV-1) in Indonesia. Biochem Cell Arch. 2020;20(August):30233027. doi:10.35124/bca.2020.20.S1.3023.

10. Bienert S, Waterhouse A, De Beer TAP, et al. The SWISS-MODEL Repository-new features and functionality. Nucleic Acids Res. 2017;45(D1):D313-D319. doi:10.1093/nar/gkw1132.

11. Maxwell PI, Popelier PLA. Unfavorable regions in the ramachandran plot: Is it really steric hindrance? The interacting quantum atoms perspective. J Comput Chem. 2017;38(29):2459-2474. doi:10.1002/jcc.24904.

12. Jespersen MC, Peters B, Nielsen M, Marcatili P. BepiPred-2.0: Improving sequence-based B-cell epitope prediction using conformational epitopes. Nucleic Acids Res. 2017;45(W1):W24W29. doi:10.1093/nar/gkx346.

13. Kharisma VD, Ansori ANM. Construction of epitope-based peptide vaccine against SARS-CoV-2: Immunoinformatics study. J Pure Appl Microbiol. 2020;14(Suppl1):999-1005. doi:10.22207/JPAM.14.SPL1.38.

14. Porter KA, Xia B, Beglov D, et al. ClusPro PeptiDock: Efficient global docking of peptide recognition motifs using FFT. Bioinformatics. 2017;33(20):3299-3301. doi:10.1093/bioinformatics/btx216.

15. Fahmi M, Kharisma VD, Ansori ANM, Ito M. Retrieval and Investigation of Data on SARS-CoV-2 and COVID-19 Using Bioinformatics Approach. In: Advances in Experimental Medicine and Biology. Springer, Cham; 2021:839-857. doi:10.1007/978-3030-63761-3 47.

16. Rigsby RE, Parker AB. Using the PyMOL application to reinforce visual understanding of protein structure. Biochem Mol Biol Educ. 2016;44(5):433-437. doi:10.1002/bmb.20966.

17. Liu X, Shi Y, Deng Y, Dai R. Using molecular docking analysis to discovery Dregea sinensis Hemsl. potential mechanism of anticancer, antidepression, and immunoregulation. Pharmacogn Mag. 2017;13(51):358-362. doi:10.4103/pm.pm 38416.

18. Kuriata A, Gierut AM, Oleniecki T, et al. CABS-flex 2.0: A web server for fast simulations of flexibility of protein structures. Nucleic Acids Res. 2018;46(W1):W338-W343. doi:10.1093/nar/gky356.

19. Desormeaux A, Coutu M, Medjahed H, et al. The Highly Conserved Layer-3 Component of the HIV-1 gp120 Inner Domain Is Critical for CD4-Required Conformational Transitions. J Virol. 2013;87(5):25492562. doi:10.1128/jvi.03104-12.

20. Dorgham K, Pietrancosta N, Affoune A, et al. Reverse immunology approach to define a new HIV-gp41-Neutralizing epitope. J Immunol Res. 2019;2019:1-13. doi:10.1155/2019/9804584.

21. Kreer C, Gruell H, Mora T, Walczak AM, Klein F. Exploiting B Cell Receptor Analyses to Inform on HIV-1 Vaccination Strategies. Vaccines. 2020;8(13):1-19. doi:10.3390/vaccines8010013. 
22. Ali M, Pandey RK, Khatoon N, Narula A, Mishra A, Prajapati VK. Exploring dengue genome to construct a multi-epitope based subunit vaccine by utilizing immunoinformatics approach to battle against dengue infection. Sci Rep. 2017;7(9232):1-13. doi:10.1038/s41598-017-09199-w.

23. Gupta S, Kapoor P, Chaudhary K, Gautam A, Kumar R, Raghava GPS. In Silico Approach for Predicting Toxicity of Peptides and Proteins. PLOS One. 2013;8(9):1-10. doi:10.1371/journal.pone.0073957.

24. Yadav S, Pandey SK, Singh VK, Goel Y, Kumar A, Singh SM. Molecular docking studies of 3-bromopyruvate and its derivatives to metabolic regulatory enzymes: Implication in designing of novel anticancer therapeutic strategies. PLoS One. 2017;12(5):1-15. doi:10.1371/journal.pone.0176403.

25. Grdadolnik J, Merzel F, Avbelj F. Origin of hydrophobicity and enhanced water hydrogen bond strength near purely hydrophobic solutes. Proc Natl Acad Sci $U S$ A. 2017;114(2):322-327. doi:10.1073/pnas.1612480114.

26. Wu P, Chaudret R, Hu X, Yang W. Noncovalent interaction analysis in fluctuating environments. $J$ Chem Theory Comput. 2013;9(5):2226-2234. doi:10.1021/ct4001087.

27. Yam-Puc JC, Toellner KM, Zhang L, Zhang Y. Role of B-cell receptors for B-cell development and antigen-induced differentiation. F1000Research. 2018;7:1-9. doi:10.12688/f1000research.13567.1.

28. Su Z, Wu Y. Computational studies of protein-protein dissociation by statistical potential and coarse-grained simulations: A case study on interactions between colicin E9 endonuclease and immunity proteins. Phys Chem Chem Phys. 2019;21(5):2463-2471. doi:10.1039/c8cp05644g. 